\title{
Pesquisa em sala de aula: As profissões sonhadas pelos alunos dos anos iniciais do Ensino Fundamental
}

\author{
The Jobs of the Dream by students of the Elementary School - Fresh \\ years
}

\author{
Aline Cristina Graef (alinegref2016@gmail.com) \\ Instituto Federal sul riograndense (IFsul) \\ Jaqueline Richter (jaquerichter86@gmail.com) \\ Universidade Federal de Rio Grande (Furg)
}

Resumo: Este artigo é um relato sobre um projeto de pesquisa realizado com 17 alunos do quarto ano do Ensino Fundamental de uma escola estadual localizada na periferia de uma cidade no Vale do Taquari. A partir da pergunta norteadora: Quais profissões são sonhadas pelos alunos do quarto ano? Os educandos, organizados em grupos por afinidade, desenvolveram a pesquisa-ação. Tiveram como objetivos conhecer a realidade profissional das famílias dos alunos, e desenvolver o interesse e a capacidade de questionar dos educandos no intuito de despertar o instinto pesquisador. Durante a pesquisa analisou-se como os estudantes procuram respostas para suas dúvidas levandoos a realizar práticas de pesquisa. As entrevistas sobre as profissões dos familiares foram quantificadas através de gráficos elaborados pelos alunos em sala de aula. Após sondagem inicial acerca de profissões sonhadas, os estudantes apresentaram dificuldade em constituir seus problemas de pesquisa. Buscou-se então uma prática de pesquisa que os auxiliasse nesse percurso. Pesquisaram a profissão de policial já que essa não havia sido escolhida por nenhum deles. Os estudantes realizaram pesquisas em jornais de circulação local e sites da internet. Apresentaram suas descobertas aos colegas da turma. Ao final do projeto, os estudantes conversaram com representantes das forças policiais pesquisadas.

Palavras-chave: Educar pela pesquisa; Projeto de pesquisa; Ensino Fundamental.

Abstract: This article report about a research Project realized with 17 students from the 4th degree at the elementary school located in the periphery of na city at Vale do Taquari. We started from a northern question: Which Jobs are dreamed by the students from the 4th degree? The students where organized in groups by afinity, the've developed a research process. Between the objectives of the research, stand out the intention of meeting the professional reality of the students Family, beyond of desenvolving the interest and the capability of question the students with the purpose of awake the research instinct. During the procces where analyzed how the students seek for answers to their doubts, taking them to realize research practices. The interviews about the parentes jobs where quantified in grafics elaborated by the students in classroom. The students realized research in journals of local circulation and internet sites, presenting, then, theyr discoveries to theyr classmates. As results, realized the relevance of the inserction of the research as a pedagogical principle at the fresh years of the scchooling of the students.

Keywords: Educate by the research; research project; students of the Fresh years.

Recebido em: $01 / 09 / 2020$

Aceito em: $27 / 10 / 2020$ 


\section{INTRODUÇÃO}

A pesquisa em sala de aula gera dúvidas e desconforto em muitos educadores. Apesar de não ser novidade, ainda é um desafio para professores que buscam aproximar-se desta nova geração de alunos que possui a liquidez como essência (BAUMAN, 2013). Estes jovens já não veem a escola da mesma forma que seus professores viam quando alunos. Não buscam os mesmos objetivos de vida que seus mestres possuíam em gerações anteriores. Esta convergência de ideias gera um movimento, que algumas vezes vai de encontro ao que acontece na sociedade e em outras vai ao encontra do que a sociedade espera.

Os educadores percebem que seus alunos mudaram, não são mais os alunos de outrora, que almejam uma carreira estável, uma família tradicional, uma profissão para a vida toda. Sua relação com a escola também mudou. "Muito se tem discutido sobre a não pertinência de modos tradicionais de ensino nas salas de aulas brasileiras. Parece ser mais fácil para o professor manter as velhas práticas docentes, mas que já não apresentam bons resultados no século XXI.” (RIBEIRO; RAMOS, 2015, p. 94).

A criança de hoje é inconstante, efêmera, volátil, impaciente e tantos outros adjetivos que retratam a pressa e falta de concentração que pudermos pensar. Mas, não são somente as crianças que estão vivendo esta modernidade líquida, todos temos pressa e num piscar de olhos trocamos, jogamos fora e excluímos (BAUMAN, 2013).

A escola possui a função formadora do aluno, porém ainda não compreende totalmente este jovem. O Educar pela Pesquisa é uma das formas de ensinar no mundo pós-contemporâneo. "No entanto, como ainda é uma ideia inovadora nos ambientes escolares, gera um movimento, geralmente implícito, de resistências" (GALIAZZI; MORAES; RAMOS, 2003, p. 2).

A busca por informações ocorre de forma espontânea nas salas de aula. A curiosidade é a forma mais comum de desenvolvimento (RIBEIRO; RAMOS, 2015). Os alunos ainda perguntam as coisas sobre as quais possuem dúvidas aos seus professores. Visto que, na opinião da maioria destes, os professores sabem responder quase tudo (GALIAZZI; MORAES; RAMOS, 2003).

Vivemos na era da informação onde nem escola, nem professores detêm o monopólio de todo o conhecimento já produzido (RADETZKE, 2019, p. 149). É comum que os alunos façam questionamentos sobre determinadas profissões, o que o profissional faz, quanto ganha, se é preciso estudar muito para desenvolver esta ou Recebido em: $01 / 09 / 2020$ 
aquela profissão. Também ocorre de ficarem nos seus grupos de afinidade discutindo o que serão no futuro (PINTO; PIBER, 2016).

A partir destes questionamentos dos alunos, acerca do seu futuro e das profissões, surgiu o interesse de levá-los a não só perguntar sobre o tema, mas pesquisar e descobrir suas próprias respostas. "O estudante pergunta sobre aquilo que tem interesse, sobre o que já sabe superficialmente, mas quer saber mais profundamente" (RIBEIRO; RAMOS, 2015, p. 96).

Com o Educar pela Pesquisa os alunos vivenciam na prática, a importância de seus questionamentos (RIBEIRO, et al., 2013). Utilizando assim suas habilidades de nativo digital. (RADETZKE, 2019). Ao buscar estimular o estudante a pesquisar algum conteúdo, espera-se que ele desenvolva o seu espírito de busca e consequentemente sua autonomia.

Em se tratando da autonomia na escolha da sua profissão, Pinto e Piber (2016, p. 190) percebem que “[...]a questão da autonomia é algo fundamental, pois os pais muitas vezes exercem influência na escolha profissional do jovem, pois alguns traçam planos para o futuro de seus filhos."

Conhecer a realidade das famílias dos estudantes envolvidos na pesquisa torna-se importante para perceber se estes estão exercendo pressão sobre a escolha profissional e seus sonhos. Da mesma forma, analisar se os alunos desejam pesquisar as profissões de seus pais ou que até viessem a desejar segui-las no futuro. É comum que os filhos acabem seguindo a profissão de seus pais. As histórias acabam se repetindo, principalmente nos aspectos em que não atingiram êxito (NOGUEIRA; NOGUEIRA, 2002).

Ao propor um projeto de pesquisa com crianças do quarto ano do Ensino Fundamental busca-se desenvolver seu interesse e capacidade de questionar. É fato que, para que haja pesquisa, é preciso haver uma pergunta. Ao se propor uma pesquisa com estudantes espera-se como um dos objetivos que estes ampliem sua capacidade argumentativa e que passem a criar perguntas mais elaboradas. No processo da pesquisa os estudantes têm possibilidade de encontrar as respostas que procuram, além de outras que surgem no decorrer do processo de pesquisa, formando um ciclo de questionamentos (GALIAZZI; MORAES, 2002). Durante a pesquisa buscamos responder ao questionamento sobre quais profissões os alunos do quarto ano sonhavam em seguir no seu futuro. Durante o processo de pesquisa várias profissões surgiram, muitas dúvidas, incertezas e a reformulação da proposta inicial. 


\section{CONTRIBUIÇÕES TEÓRICAS}

A investigação realizada pelos alunos teve como procedimentos a pesquisa bibliográfica e as entrevistas realizadas com os familiares. Para desenvolver a pesquisa as famílias assinaram o termo de consentimento livre e esclarecido permitindo que seus filhos participassem. Assim como assinaram um breve termo escrito pelos alunos, ao participarem da entrevista realizada por estes.

A pesquisa bibliográfica deu-se em jornais de circulação na cidade e em sites da internet. "A pesquisa bibliográfica, ou de fontes secundárias, abrange toda bibliografia já tornada pública em relação ao tema de estudo, desde publicações avulsas, boletins, jornais, revistas, livros, pesquisas, monografias, teses, material cartográfico, etc." (LAKATOS; MARCONI, 2003, p. 181).

Os instrumentos utilizados pelos estudantes para o levantamento de dados foram as entrevistas realizadas com os familiares. A entrevista estruturada foi elaborada em sala de aula, pelos alunos com ajuda do professor. Optou-se pela entrevista estruturada, pois nela "[...] o entrevistador segue um roteiro previamente estabelecido; as perguntas feitas ao indivíduo são predeterminadas.” (LAKATOS; MARCONI, 2003, p. 197).

Deu-se especial atenção a esta etapa, visto que era novidade para os alunos, além de sua importância na pesquisa. "A preparação da entrevista é uma etapa importante da pesquisa: requer tempo (o pesquisador deve ter uma ideia clara da informação de que necessita) e exige algumas medidas.” (LAKATOS; MARCONI, 2003, p. 199).

Os alunos realizaram a abordagem qualitativa dos dados obtidos com as entrevistas. Como as entrevistas foram estruturadas, os dados puderam ser analisados com facilidade, pois as respostas seguiram o roteiro. Utilizando gráficos e tabelas conseguiram identificar de forma clara os resultados obtidos nas entrevistas com os familiares.

$\mathrm{Na}$ pesquisa bibliográfica sobre a profissão policial, fizeram abordagem qualitativa de dados e informações.

\subsection{CONTEXTO DA PESQUISA}

A escola em que a pesquisa foi realizada está situada em uma região de periferia, com alto índice de violência e tráfico de drogas. O educandário possui em média 
duzentos e cinquenta alunos e atende do pré-escolar até o nono ano do Ensino Fundamental, atendendo nos turnos matutino e vespertino. Atualmente está cedendo duas salas de aula para a rede municipal onde são atendidos em média trinta alunos da Educação Infantil - pré-escolar. A escola não oferece atividades no contraturno das aulas.

A infraestrutura da escola está bastante defasada, visto que sua inauguração data de 12 de setembro de 1960. Houve reformas e ampliações, porém a estrutura original se manteve com o passar dos anos. O laboratório de informática possui onze computadores para uso dos alunos e um para uso dos professores. Há conexão de internet na sala de informática, porém seu sinal oscila e frequentemente apresenta problemas.

A turma do quarto ano possui dezessete alunos matriculados. Destes, quatro possuem currículo adaptado, por terem necessidades educacionais especiais. Por haver alunos com necessidades educacionais especiais na turma é preciso que todas as propostas sejam pensadas para as capacidades de cada um. "Assim, mesmo tendo como meta o desenvolvimento destas capacidades em todos os participantes, é preciso respeitar os potenciais de cada aluno nos diferentes estágios de sua formação." (GALIAZZI; MORAES, 2002, p. 246).

$\mathrm{O}$ aluno mais jovem da turma possui nove anos de idade e o mais velho possui dezesseis anos. A disparidade de idade é um desafio à parte, visto a diferença de interesses destes estudantes. A maioria das famílias dos estudantes reside nas proximidades da escola, desta forma podem ir e vir caminhando de suas casas até o educandário.

\subsection{PESQUIS EM SALA DE AULA}

A proposta de realizar e educar pela pesquisa não é nova. Mas, também não pode ser encarada como algo rotineiro nas escolas. Os estudantes frequentemente cercados de alternativas sociais e tecnológicas que podem ser problematizadas e compreendidas (RIBEIRO; RAMOS, 2015). Colocar o aluno como autor/pesquisador muda o antigo paradigma da sala de aula e automaticamente a postura do professor. "Na medida em que considera o conhecimento do aluno, permite estabelecer intensas relações com o cotidiano, possibilitando, desse modo, superar seu conhecimento de um modo contextualizado." (FRESCHI; RAMOS, 2009, p. 158). 
Este novo conhecimento pesquisado será muito mais facilmente assimilado. As ressignificações ocorrerão na prática cotidiana da sala de aula. "Cabe salientar ainda que, quanto maior o contato com a pesquisa na sala de aula, maior será a capacidade de crítica, criação, discussão, escrita, argumentação, debate, questionamento e comunicação desenvolvida junto com o aluno.” (FRESCHI; RAMOS, 2009, p. 157).

O ensino pela pesquisa permite um aprendizado com sentidos pois o estudante se sente parte desta construção, além de levá-lo a superar o conhecimento produzido pelo senso comum, chegando a uma reconstrução dos conhecimentos científicos. (THIESEN; RIBEIRO, 2018, p. 604).

A prática da pesquisa levará tanto o professor a perceber e utilizar formas mais adequadas de aprendizagem, como fará o aluno melhorar num todo. O papel do professor é fundamental na prática da pesquisa desenvolvida pelos alunos (RIBEIRO, et al., 2013). Pois, será necessário ensinar e moldar os alunos para que compreendam esta metodologia. "A pesquisa em sala de aula busca construir respostas para indagações, articulando pensamentos e argumentos e reconstruindo os saberes dos estudantes." (RIBEIRO, et al., 2013, p. 2).

Através da investigação a aprendizagem segue outro rumo. Com esta metodologia o professor capacita seus alunos a desenvolverem a reflexão, o contraste, o debate e o enriquecimento com teorias e experiências comuns a todos que participaram efetivamente da proposta. "As escolas se transformam em centros de desenvolvimento profissional." (GALIAZZI; MORAES; RAMOS, 2003, p. 5).

Essas vivências práticas irão levando os alunos a ampliarem seus conhecimentos e estes irão desenvolvendo sua argumentação e sua criatividade. Assim aos poucos, pesquisa após pesquisa estes alunos irão criando confiança e autonomia. Desenvolvendo suas habilidades, ampliando seus conhecimentos iniciais, pois serão questionadores com conhecimentos dos fundamentos da pesquisa. Enfim, haverá relação entre o que é estudado na escola e a vida cotidiana dos alunos. A pesquisa em sala de aula traz o aluno para o papel de protagonista de sua própria aprendizagem. (RIBEIRO; RAMOS, 2015).

As tecnologias estão à nossa volta e seria desafiador viver sem elas. Seja a caneta esferográfica ou a energia elétrica todos os aparatos tecnológicos são hoje considerados fundamentais. As crianças que nasceram após o advento da internet são ainda mais 
dependentes da tecnologia. Afinal, não conhecem outra forma de vida que não seja esta (RADETZKE, 2019).

A proposta de Educar pela Pesquisa não pode estar desligada da utilização da internet e das ferramentas digitais. O professor precisa estar capacitado para auxiliar e mobilizar seus alunos para a utilização didática das ferramentas digitais. Pois, a gama de informações disponíveis na rede é tão grande que somente com orientação os educandos conseguirão compreender e prevenir-se (FORESTI; TEIXEIRA, 2012).

\section{DESENVOLVIMENTO DA INVESTIGAÇÃO}

Os alunos realizaram entrevistas com os familiares para levantamento de dados a respeito das profissões destes. "A entrevista tem como objetivo principal a obtenção de informações do entrevistado, sobre determinado assunto ou problema." (LAKATOS; MARCONI, 2003, p. 196).

Em sala de aula construíram um gráfico com as respostas obtidas nas entrevistas. Após a análise de dados, os alunos realizaram um levantamento das profissões que conheciam. As profissões citadas pelos alunos foram desenhadas e os desenhos colados em um cartaz que ficou exposto na sala de aula.

Então escolheram uma profissão que gostariam de estudar/pesquisar. "A pesquisa em sala de aula busca construir respostas para indagações dos participantes, articulando pensamentos e argumentos e reconstruindo os saberes dos estudantes e do professor" (RIBEIRO; RAMOS, 2015, p. 96).

Cada aluno pode livremente fazer sua escolha. Novamente fizeram desenhos e estes foram colados em outro cartaz igualmente exposto na sala de aula. Neste momento criaram algumas perguntas, escreveram dúvidas que possuíam sobre esta profissão que desejavam pesquisar. "As perguntas apresentadas pelos estudantes decorrem de seu conhecimento e de suas experiências de vida, bem como de sua curiosidade e de suas observações do entorno" (RIBEIRO; RAMOS, 2015, p. 97). Como tiveram muita dificuldade nesta etapa decidiu-se trabalhar inicialmente de forma coletiva.

$\mathrm{Na}$ reelaboração da proposta, passou-se a trabalhar com os alunos de forma coletiva. Escolheu-se então uma das profissões não citadas pelos estudantes no levantamento inicial para que todos realizassem esta primeira pesquisa de forma conjunta. "Como precursor da prática do Educar pela Pesquisa, um levantamento das 
dúvidas e curiosidades que os estudantes apresentam sobre o objeto de estudo é um importante ponto de partida" (RIBEIRO; RAMOS, 2015, p. 97). Os alunos escreveram suas dúvidas/questionamentos sobre a profissão escolhida. Estes apontamentos foram colocados num cartaz para posterior análise da turma.

A partir deste levantamento de informações os alunos foram levados a criar questionamentos, dúvidas sobre a profissão de policial. Por se tratar de uma região de periferia com alto índice de criminalidade, os alunos possuíam uma visão bastante negativa e deturpada do papel da polícia. Alguns questionamentos giraram em torno das agressões infundadas, de provas plantadas para incriminar inocentes, quais armas os policiais tinham acesso, entre outros. Os questionamentos foram colados em um cartaz que ficou exposto na sala de aula.

Os alunos foram divididos em grupos para que escolhessem um questionamento para ser respondido. Utilizaram diferentes recursos para a pesquisa. Inicialmente realizaram buscas em jornais, onde perceberam que seu município possuía capitão e delegado, identificaram que alguns policiais utilizavam uniformes e outros não. "As discussões podem tornar-se molas propulsoras da reflexão individual, colaborando para a constituição dos sujeitos." (NOVAKOWSKI KIEREPKA; ZANON, 2019, p. 8). As descobertas eram apontadas pelos grupos e geralmente tornavam-se pequenas discussões.

Este processo de questionar e rever os questionamentos iniciais é fundamental para que o aluno faça a reconstrução de suas produções. Para então, a partir desta análise, construir novos argumentos (GALIAZZI; MORAES, 2002). Nesta primeira etapa vários alunos perceberam que haviam encontrado respostas para suas dúvidas. Outros constataram que seus questionamentos não estavam formulados de forma adequada. Houve ainda aqueles que criaram novas interrogações acerca do tema pesquisado.

Conforme novas dúvidas foram surgindo, algumas concepções prévias foram sendo descartadas. Num segundo momento, os alunos foram à sala de informática para realizarem pesquisas na rede de internet, na busca de responder sua pergunta de pesquisa. Ficou combinado que cada grupo faria sua pesquisa, levantaria dados, imagens e depois apresentaria aos colegas da turma.

Os alunos puderam escolher a forma de apresentação dos resultados obtidos. Instigou-se a utilização de projeção com um programa de edição de slides, para levá-los a ampliar seus conhecimentos na utilização das ferramentas tecnológicas. 
Com muito auxílio conseguiram realizar a montagem e organização dos slides. A apresentação foi realizada em sala de aula, somente para os colegas (a pedido dos próprios estudantes). Ao final das apresentações foi realizado um questionário escrito sobre as projeções. Neste questionário puderam descrever quais aspectos foram positivos, os aspectos negativos e quais mudanças poderiam ser feitas para as próximas apresentações. No questionário também descreveram as dúvidas que ainda possuíam sobre a profissão de policial.

O questionário foi preenchido sem a indicação de autoria. Houve liberdade para realizar os apontamentos que considerassem relevantes. As respostas foram lidas e discutidas pela turma. "Reflexões coletivas podem proporcionar uma discussão sobre ideias, que podem ser aceitas e engendrarem reflexões singulares" (NOVAKOWSKI KIEREPKA; ZANON, 2019, p. 8).

Para fechamento da proposta de pesquisa os alunos receberam a visita do delegado da delegacia de Polícia Civil da cidade. Puderam fazer perguntas e conversar com ele. Em outra data receberam a capitão da Brigada Militar onde novamente realizaram questionamentos e conversaram. Num terceiro momento foram levados ao quartel do corpo de Bombeiros onde conheceram todo o trabalho que os bombeiros militares desenvolvem e puderam dar um passeio no caminhão de bombeiros.

Ao final da proposta de pesquisa, os estudantes confeccionaram um cartaz coletivo onde descreveram tudo que aprenderam sobre a polícia. "A escola como um espaço de sistematização, organização e discussão deve priorizar por essas relações uma vez que são contribuintes da formação do sujeito" (RADETZKE, 2019, p. 149).

Ao término da leitura coletiva dos apontamentos deste cartaz, os estudantes voltaram aos cartazes anteriores para refletirem sobre as perguntas que haviam escrito no início da pesquisa. Também analisaram os conhecimentos prévios que possuíam sobre a profissão pesquisada. Para síntese da pesquisa os alunos criaram um novo cartaz com os conhecimentos adquiridos.

\section{ANÁLISE DAS INFORMAÇÕES PRODUZIDAS NA INVESTIGAÇÃO}

Ao realizarem as entrevistas com os familiares os alunos iniciaram a primeira etapa de sua pesquisa. Na qualificação dos dados, realizada de forma coletiva, uma 
tabela com todas as informações obtidas nas entrevistas com os familiares foi construída. Os alunos entrevistaram pais, tios e avós.

Para melhor compreensão estas profissões serão relacionadas aqui em ordem alfabética, com a quantidade de respostas obtidas pelos alunos em suas entrevistas com os familiares: Agricultor- 21; Autônomo- 2; Auxiliar de produção- 2; Babá- 1; Caminhoneiro- 4; Carregador- 1; Costureira- $\quad 7$; Cozinheira- $\quad 4$; Desossadora (frigorífico de frangos)- 1; Doméstica- 3; Faxineira- 2; Fumicultor- 8; Funileiro- 4; Jardineiro- 1; Mecânico- 2; Montador- 1; Oleiro- 1; Operador de empilhadeira- 1; Pedreiro- 4; Polidor- 1; Promotor de vendas- 2; Reciclador- 5; Revisora- 1; Safrista- 7; Serralheiro- 1; Servente- 1; Varredeira- 1; Vendedora- 1; Vigilante- 1.

Depois de construir a tabela os alunos buscaram compreender qualitativamente as informações. Como tiveram dificuldade, um gráfico foi construído de forma coletiva em sala de aula. A partir da construção do gráfico os alunos conseguiram perceber os dados obtidos nas suas entrevistas.

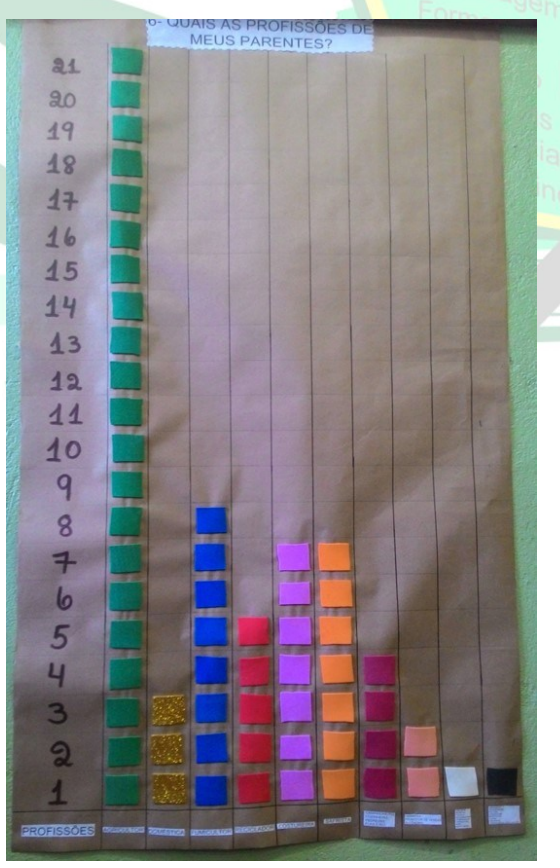

Figura 1 - Gráfico produzido a partir da análise das entrevistas com os familiares. (Fonte: Acervo das autoras).

Ao analisar estes dados ficou evidente que nem eles imaginavam que haveria tantos agricultores entre seus familiares, alguns ficaram impressionados com a diversidade de profissões. Muitos alunos utilizaram o termo safrista. A escola está 
localizada num município com grande presença de empresas do ramo tabacaleiro, os cargos em regime sazonal são denominados safristas.

Com a análise de dados, foi possível explicar aos alunos que o termo safrista se refere ao tempo de contrato e não ao cargo/função que desempenham. Com estas conceituações alguns estudantes perceberam que tanto a tabela quanto o gráfico estavam incorretos. Mas, como pesquisa inicial decidiu-se manter os dados.

Após a análise dos dados das profissões das famílias partiu-se para o despertar para a pesquisa/investigação. De forma coletiva os estudantes fizeram um levantamento de todas as profissões que lembravam. Estas foram desenhadas e coladas em um cartaz que ficou exposto na sala de aula. Cada estudante escolheu uma profissão de seu interesse ou que gostaria de pesquisar.

Os estudantes não escolheram as profissões dos pais. O que chamou atenção, pois nos momentos de oralidade os pais parecem ter muita influência sobre suas vidas. Este fato pode ter ocorrido, pois os pais possuem funções subalternas, ou por que os estudantes ainda são jovens e possuem uma visão fantasiosa sobre o trabalho. Pinto e Piber (2016, p. 189) trazem que “[...] muitas vezes os jovens escolhem uma profissão baseada em influências dos pais ou do grupo social do convívio do sujeito e deixam de pensar sobre os aspectos da sua personalidade e de suas características pessoais."

Ao realizar os levantamentos de dúvidas e aspectos que gostariam de pesquisar sobre a profissão escolhida, ficou evidente que os estudantes necessitavam amadurecer na argumentação. "Como a estrutura do educar pela pesquisa é flexível, sustentada na argumentação por meio do diálogo, da leitura e da escrita, os alunos se desestabilizam com a autonomia que lhe é conferida para aprender." (GALIAZZI; MORAES; RAMOS, 2003, p.10).

Realizou-se um levantamento sobre as profissões que não foram escolhidas por nenhum aluno e que despertavam interesse para a primeira pesquisa. Por votação a profissão policial foi a escolhida.

Iniciou-se a análise de conhecimentos prévios dos alunos acerca da profissão alvo da pesquisa. Para esta etapa foi confeccionado um cartaz coletivo com estas informações. "Sugerimos, pois, que o conhecimento inicial, que é sempre um conhecimento em processo, seja registrado para que o trabalho de pesquisa possa ser sistematizado a partir dele." (GALIAZZI; MORAES; RAMOS, 2003, p. 7).

Após esta etapa os estudantes responderam novo questionamento sobre o que gostariam de saber sobre o policial. Os questionamentos foram novamente colocados 
em um cartaz coletivo que foi exposto na sala de aula, em companhia do primeiro. Os estudantes dividiram-se em grupos por afinidade. Cada grupo foi incumbido de escolher um questionamento para ser respondido/pesquisado.

“A consideração sobre a importância da pergunta do estudante passa pela compreensão do professor no sentido de que aprender não é somente o acúmulo de informações e conhecimento.” (RIBEIRO; RAMOS, 2015, p. 98). Houveram grupos que criaram questionamentos muito relevantes e significativos. Já outros criaram questionamentos incompreensíveis, ou óbvios. Mas, na proposta de Educar pela Pesquisa toda pergunta merece ser pesquisada. Os estudantes foram levados a acreditar que suas dúvidas eram muito relevantes e que trariam conhecimentos para todo o grupo.

A pesquisa bibliográfica deu-se num primeiro momento em jornais de circulação municipal. Com a pesquisa bibliográfica alguns estudantes foram percebendo que suas concepções iniciais estavam incorretas, ou que a formulação não estava adequada. Num segundo momento, a pesquisa deu-se na sala de informática. Pesquisaram em diferentes sites da internet na busca por esclarecer/responder seu questionamento.

Tiveram grande dificuldade em realizar esta etapa da pesquisa. Ficou evidente a necessidade de aumentar e melhorar a leitura, a interpretação, a argumentação. Percebeu-se que educar pela pesquisa exige um discurso competente (GALIAZZI; MORAES; RAMOS, 2003).

Com as informações coletadas, foram desafiados a apresentar os resultados aos seus colegas. Um programa editor de slides foi utilizado para a elaboração das apresentações. Durante a elaboração das apresentações os educandos tiveram muita dificuldade, não conheciam o programa, nem suas funcionalidades. A educação deve oportunizar momentos de formação aos estudantes que permitam o desenvolvimento de distintas capacidades (FRESCHI; RAMOS, 2009).

Após as apresentações para os pares, realizaram uma avaliação sobre o conteúdo dos slides, sobre a postura dos colegas e uma análise de sua conduta. Ao final da avaliação analisaram se suas dúvidas/questionamentos haviam sido respondidas.

A avaliação pode ocorrer de diferentes formas, é fundamental que os estudantes tenham momentos para observar e analisar suas produções e as produções dos pares, perceber crescimentos e possíveis evoluções. Assim como diagnosticar os aspectos que ainda necessitam mais dedicação (GALIAZZI; MORAES, 2002). 
Como muitas dúvidas do cartaz ainda persistiam, foram convidados a criar perguntas sobre as dúvidas que ainda possuíam para entrevistar o delegado da Polícia Civil, a capitão da Brigada Militar e o capitão do corpo de Bombeiros da cidade.

Durante a entrevista com o delegado fizeram vários questionamentos sobre a profissão, as funções que ele desempenha em seu cargo. Alguns questionamentos abordaram como o profissional lidava com o medo. Realizaram perguntas referentes ao salário do profissional e formação. Interessaram-se em saber se este sonhava em ser delegado desde criança, entre outras tantas perguntas.

Ao entrevistarem a capitão da Brigada Militar já estavam mais habituados, foram mais diretos nas perguntas. Os questionamentos seguiram na mesma linha das perguntas feitas ao delegado. Mas, como ela estava com roupa oficial e armada focaram-se mais nas questões relativas às armas. Um dos questionamentos interessantes foi se a capitão já havia prendido algum vereador, prefeito ou presidente. Neste momento a profissional pode explicar aos alunos o foro privilegiado e o funcionamento dos três poderes.

$\mathrm{Na}$ visita ao corpo de Bombeiros tiveram uma experiência mais completa, pois se deslocaram até o local de trabalho destes. Puderam ver os caminhões e todo o espaço físico do quartel. "Para as crianças dos anos iniciais isto é fundamental, considerando que elas ainda necessitam muito do corpo para compreender, assimilar e tornar informação em conhecimento." (THIESEN; RIBEIRO, 2018, p. 604).

$\mathrm{Na}$ conversa fizeram perguntas relacionadas aos objetos que viam em sua volta. Alguns estudantes repetiram as perguntas que fizeram aos profissionais anteriormente entrevistados. Novamente fizeram questionamentos referentes ao medo e ao sonho de infância com a profissão. A relação da pesquisa com a realidade prática investigada fundamenta e exemplifica os argumentos construídos. Podendo tornar-se uma forma de validação (GALIAZZI; MORAES, 2002).

Ao final da pesquisa os educandos avaliaram as informações adquiridas, sua postura, e a postura dos colegas. Foram levados a pensar quais aprendizagens construíram. Neste momento ainda analisaram como a pesquisa foi desenvolvida, o que aprenderam sobre o tema, onde procurar respostas e a avaliar a qualidade das informações obtidas. A apresentação das respostas das perguntas deu-se em sala de aula e foi uma forma de apresentar os resultados aos colegas. 


\section{CONSIDERAÇÕES FINAIS}

Mobilizar alunos de quarto ano do Ensino Fundamental-Anos Iniciais para desenvolverem pesquisas pode soar utópico. A turma envolveu-se na proposta e teve bastante empenho e dedicação. Compreender e pesquisar suas dúvidas foi um dos processos iniciais abordado nesta pesquisa.

O Educar pela Pesquisa é uma das formas de fazer com que os estudantes participem ativamente de seu desenvolvimento, de sua aprendizagem. Os alunos do quarto ano puderam descobrir as respostas para seus questionamentos iniciais acerca da profissão de policial.

A proposta de realizar um projeto de pesquisa a partir da curiosidade/ questionamento dos estudantes trouxe desafios ao educador, por alterar a proposta curricular e buscar através da pesquisa e das atividades desenvolvidas com os alunos constituir e ressignificar o plano de trabalho.

Um dos desafios da proposta foi a pouca habilidade dos estudantes para com as ferramentas tecnológicas. Em se tratando de nativos digitais perceber que a digitação no teclado e o uso do mouse são desafios, pode ser chocante. $\mathrm{O}$ mau funcionamento das ferramentas digitais e equipamentos, aliada à baixa qualidade dos materiais disponíveis na escola podem ser preditores de seu pouco uso para fins didáticos.

Outro aspecto desafiador foi a pouca habilidade em interpretar textos lidos. Os textos pesquisados, tanto na internet, como em jornais, possuíam uma linguagem muito formal e de difícil interpretação para os estudantes. A dificuldade em compreender as informações fez com que alguns se desmotivassem, outros ficaram procurando, procurando e não conseguiam encontrar respostas que compreendessem.

Nos diálogos em sala de aula que se sucederam após a pesquisa os educandos foram questionados sobre os locais em que buscavam respostas para suas dúvidas, alguns relataram não ter dúvidas, outros relataram questionar os pais ou a professora e dois referiram-se a sites de vídeos.

Quanto ao tema pesquisado os estudantes apresentaram muitas informações distorcidas no levantamento de informações prévias. Muitos acreditavam que o serviço militar obrigatório era a única forma de se tornar policial. Também não diferenciavam as corporações. Após as apresentações das respostas, passaram a trazer recortes de jornais para as aulas, principalmente com fotos. Os meninos dialogavam frequentemente sobre o exército fazendo relações com familiares e conhecidos que haviam prestado o 
serviço militar obrigatório. Algumas meninas fizeram questionamentos sobre as mulheres nas forças armadas e passaram a falar sobre distintas profissões que gostariam de seguir.

Foram aos poucos percebendo que a profissão pesquisada fazia parte da realidade deles de formas diferentes das quais eles haviam descrito na sondagem inicial. O projeto de pesquisa desmistificou muitas informações deturpadas que os estudantes detinham. Com o Educar pela Pesquisa passaram a ter autonomia para sugerir assuntos para pesquisas e trouxeram suas curiosidades para as aulas.

Os alunos do quarto ano não aprenderam a metodologia de pesquisa científica, mas perceberam que todo e qualquer assunto pode ser perguntado e a partir da pergunta diferentes respostas podem ser obtidas.

Neste relato não abordamos a totalidade do projeto de pesquisa desenvolvido com a turma. Esta pesquisa desenvolvida em conjunto pelos grupos de afinidade foi um ensaio inicial do Educar pela Pesquisa que se seguiu com o andamento do projeto onde os educandos do quarto ano aplicaram questionários com os estudantes de todas as turmas da escola. No questionário buscaram identificar quais eram as profissões sonhadas pelos alunos da escola. O resultado desta pesquisa foi apresentado na mostra pedagógica da escola.

\section{REFERÊNCIAS}

BAUMAN, Zygmunt. A cultura do mundo líquido moderno. Rio de Janeiro: Zahar, 2013.

BORDIEU, Pierre, 1930-2002. A economia das trocas simbólicas. São Paulo: Perspectiva, 2007.

CAETANO, H., MIRANDA, G. L. e SOROMENHO, G. (2010). Comportamentos de risco na internet: um estudo realizado numa escola do ensino secundário, Revista Latinoamericana de Tecnología Educativa - RELATEC, 9 (2), 167185. Disponível em: $<$ http://campusvirtual.unex.es/revistas/index.php?journal=relatec $>$. Acesso em: 25 mai. 2017.

CAMARGO, Andrea Norema Bianchi de et al. Alfabetização científica: a evolução ao longo da formação de licenciandos ingressantes, concluintes e de professores de Química. Momento - Diálogos em Educação, [S.1.], v. 20, n. 2, p. 19-29, maio 2012. ISSN ISSN 2316-3100. Disponível em:

$<$ https://seer.furg.br/momento/article/view/2425/1404>. Acesso em: 10 jun. 2017.

DEMO, Pedro. Educar pela Pesquisa. Campinas: Editora Autores Associados, 2011. 
DEMO, Pedro. Pesquisa: princípio científico e educativo. 12. ed. - São Paulo: Cortez, 2006. (Biblioteca da educação. Série 1. Escola; v. 14). ISBN 85-249-0282-5.

FORESTI, Andressa, TEIXEIRA, Adriano Canabarro. Proposta de um conceito de aprendizagem para a era digital RELATEC Revista Latinoamericana de Tecnología Educativa. Revista Latinoamericana de Tecnología Educativa, Vol. 11 (1) (2012). ISSN 1695 $\neg 288 X$. Disponível em: <http://campusvirtual.unex.es/revistas>. Acesso em: 12 mai. 2017.

FRESCHI, Márcio, RAMOS, Maurivan Güntzel. Unidade de Aprendizagem: um processo em construção que possibilita o trânsito entre senso comum e conhecimento científico, Revista Electrónica de Enseñanza de las Ciencias. Vol.8, №1 (2009). Disponível em: <http://reec.uvigo.es/volumenes/volumen8/ART9_Vol8_N1.pdf>. Acesso em: 25 mai. 2017.

GALIAZZI, Maria do Carmo, MORAES, Roque, RAMOS, Maurivan Güntzel. Educar pela pesquisa: as resistências sinalizando o processo de profissionalização de professores, Revista Educar, Curitiba, n. 21, p. 227-241. 2003. Editora UFP. Disponível em: <http://revistas.ufpr.br/educar/article/view/2132>. Acesso em: 25 mai. 2017.

GALIAZZI, Maria do Carmo, MORAES, Roque. Educação pela pesquisa como modo, tempo e espaço de qualificação da formação de professores de ciências, Revista Ciência \& Educação, v. 8, n. 2, p. 237-252, 2002. Disponível em:

$<$ http://www.scielo.br/pdf/ciedu/v8n2/08.pdf>. Acesso em: 25 mai. 2017.

LAKATOS, Eva Maria, MARCONI, Marina de Andrade. Fundamentos de metodologia científica, 5. Ed. - São Paulo: Atlas 2003.

LÓPEZ, José Manuel Saez. Valoración del impacto que tienen las TIC en educación primaria en los procesos de aprendizaje y en los resultados a través de una triangulación de datos. Revista Latinoamericana de Tecnología Educativa - RELATEC, Vol. 10 (1) (2011). ISSN 1695 2288X. Disponível em: <http://relatec.unex.es/article/view/867>. Acesso em: 25 mai. 2017.

MONTOVANI, Renata Forcato, LOPES, Geniela, AVILA, Renato Nogueira Perez, GONÇALVES, Patrícia Motta Cordeiro. Uma demonstração da importância de promover o autoconhecimento na orientação profissional. Revista extendere. Vol. $2, \mathrm{n}^{\circ}$ 1. jan a jun 2014. ISSSN 2318-2350. Disponível em:

$<$ http://periodicos.uern.br/index.php/extendere/article/viewFile/1267/722>. Acesso em: 25 mai. 2017.

NOGUEIRA, Cláudio Marques Martins; NOGUEIRA, Maria Alice. A sociologia da educação de Pierre Bourdieu: limites e contribuições. Educ. Soc., Campinas, v. 23, n. 78, p. 15-35, abr. 2002. Disponível em:

$<$ http://www.scielo.br/scielo.php?script=sci_arttext\&pid=S0101$73302002000200003 \& \operatorname{lng}=$ pt\&nrm=iso $>$. Acesso em 06 jan. 2018.

NOVAKOWSKI KIEREPKA, J.; ZANON, L. B. Problematização e reconhecimento de teorias e práticas de professores em formação para o ensino de Ciências com foco no educar pela pesquisa. Revista Insignare Scientia - RIS, v. 2, n. 1, p. 1-20, 20 maio 2019.

PINTO, Patrícia Feiten, PIBER, Lizete Dieguez. Orientação profissional nas escolas de rede pública: um relato de experiência. Vivências: Revista Eletrônica de Extensão da URI, Vol. 12, N.23: p.188-196, Outubro/2016. ISSN 1809-1636. Disponível em: 
$<$ http://periodicos.uern.br/index.php/extendere/article/viewFile/1267/722>. Acesso em: 25 mai. 2017.

RADETZKE, F. O Ensinar e o Aprender por meio de Projetos: cooperação e cidadania. Revista Insignare Scientia - RIS, v. 2, n. 3, p. 142-153, 21 nov. 2019.

RIBEIRO, Marcus Eduardo Maciel et al. O educar pela pesquisa como proposta de reorganização curricular: relato de uma atividade de formação de professores. Anais do 33 Encontro de Debates sobre o Ensino de Química, 2013.

RIBEIRO, Marcus Eduardo Maciel; RAMOS, Maurivan Güntzel. A pesquisa no currículo escolar: ações que valorizam as perguntas dos estudantes. In: SANTOS, Sandra Aparecida dos; RIBEIRO, Marcus Eduardo Maciel. Ensino de Ciências: reflexões e diálogos. Rio do Sul: UNIDAVI/PROPPEX, 2015.

THIESEN, Júlia Grasiela; RIBEIRO, Marcus Eduardo Maciel. A influência da iniciação à pesquisa na construção da aprendizagem no ensino de Ciências nos anos iniciais: relato de uma prática docente. Revista Thema, v. 15, n. 2, p. 603-620, 2018.

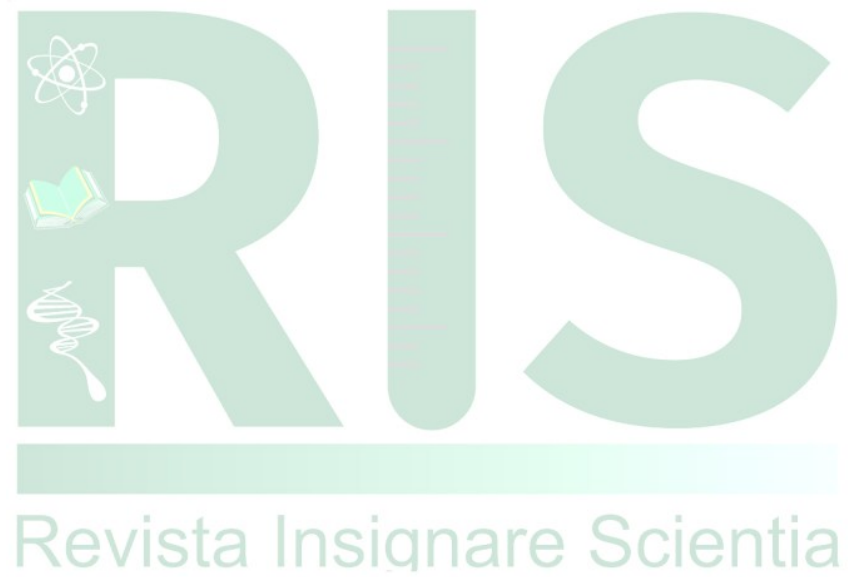

